\title{
Centrifugal Model Testing for Deformations in High-Filling Foundation of Loess in a Gully
}

\author{
Kai WU, Wankui NI, Longshuai XU
}

\begin{abstract}
A major problem of concern in high-filling engineering is settlement deformations in filling foundation. Such deformations are affected by many factors. In this study, a large-scale centrifugal model test was carried out to study the deformation of high-filling foundation of loess in a gully area, under the conditions of natural water content and rising groundwater respectively. The treatment technology between the original mountain slope and the filling body was also investigated. It was found that the settlement deformations of the high-filling foundation mainly occurred under the condition of increasing centrifugal acceleration. The settlement rate also increased in this process, and the final settlement increased with filling thickness. When the groundwater in the filling body rose, additional settlement in the filling foundation occurred which readily leads to foundation destabilization. Improving the compactness had a significant effect on reducing this additional settlement. Adopting a stepped treatment method to overlap the original mountain slope, the filling body helped to decrease the settlement of the filling foundation above the joint. However, it was not conducive to controlling the settlement of the adjacent filling body. The slope of the original mountain should be taken into account in the design of the overlapping method. For the overlapping region between the filling body and the original rock mass, permeable materials should be installed in the joint which can be compacted to form a permeable zone, which in turn could connect to a drainage pipeline laid at the bottom of the gully. The bedrock fissure water is then efficiently drained and the water infiltrating into the filling body reduced. This could help to avoid a large amount of additional settlement and is beneficial to the foundation's stability after construction.
\end{abstract}

Keywords: centrifugal; groundwater; gully area; high-filling foundation; overlapping method; settlement deformation

\section{INTRODUCTION}

The Loess Plateau in China is famous for the extensive distribution and thickness of loess. With the implementation of China's western development strategy, western urban expansion and economic development are progressing in parallel. Due to the special geological and topographical conditions of the Loess Plateau, there is a shortage of available land resources, so land reclamation projects are gradually increasing, especially in the gully area [1-4]. Loose loess is used to fill in the gully which then forms the foundation after compaction. Deformations in the settled foundation have become an issue of paramount importance. It is a complex problem and the main calculation methods used in its analysis include hierarchical summation methods, numerical calculation techniques, and model prediction methods [5-15]. As foundation settlement deformation is a slow process and the deformation mainly comes from the material weight or other factors related to the weight, generalized model tests cannot truly reflect the actual state of stress and strain in the process. Furthermore, these generalized model tests are very time-consuming. However, a geotechnical centrifugal model test can reproduce the weight stress conditions with excellent similarity, and thus has been widely adopted in various fields of research [16-22]. In recent years, some important advancement has been made in the field of loess research on the failure mechanism and stability of the filling foundation using centrifugal model testing [23-29]. However, filling in the gully area will certainly change the groundwater seepage path and break the seepage balance of the groundwater. Poor drainage conditions will raise water levels and threaten the stability of the foundation. To date, little research has focused on this aspect of centrifugal model test. Similarly, research on the treatment technology of the joint between the filling foundation and the original mountain slope is lacking. Therefore, it is necessary to conduct further studies to improve the loess high-filling foundation settlement control technology. Based on the loess high-filling engineering in a gully area of Yan'an, this paper investigates the deformations in the filling foundation and the treatment technology of the joint between the filling body and the original mountain slope. Centrifugal model tests were carried out to study the deformations of high-filling foundation under the conditions of natural water content and rising groundwater respectively. The results of these tests were discussed in terms of settlement, earth pressure, pore water pressure and the relationship between settlement and rising groundwater level. The research results may provide references for the design and construction of similar projects.

\section{LOESS SAMPLES}

Taken from a high-filled site in the gully of Yan'an, the test loess samples were greyish yellow. The physical properties of five test samples were determined according to the Chinese National Standards (CNS) GB/T501231999 [30]. The soil was mostly fine-grained in which the clay ranged from $9.29-9.45 \%$, the silt content was within $80.79-81.92 \%$ and fine sand accounted for $8.63-10.15 \%$ of the samples. The D50 and uniformity coefficient were respectively $26.89-27.63 \mu \mathrm{m}$ and $12.04-12.98$. The specific gravity of the samples was $2.69-2.71$. The liquid and plastic limits were within the range 25.2-25.8 and 15.9-17.1, respectively. Tab. 1 lists the key properties of the five soil samples and the particle size distribution is shown in Fig. 1. The test results showed that the soil is classified as silt, according to CNS GB/T50123-1999. A light compaction test found that the optimum water content was $14 \%$ and the maximum dry density was 1.78 $\mathrm{g} / \mathrm{cm}^{3}$, the results of which are shown in Fig. 2.

\section{CENTRIFUGAL MODELLING OF HIGH-FILLING FOUNDATION \\ 3.1 Centrifugal Testing Machine}

The centrifugal testing machine used in this research is a LXJ-4-450 held by China's Institute of Water Resources and Hydropower Research. Its rotational radius is $5.03 \mathrm{~m}$

The maximum effective centrifugal load is $1.5 \mathrm{t}$ and 
the limit of centrifugal acceleration is $300 \mathrm{~g}$. The maximum size of the model box is $1500 \mathrm{~mm}$ in length and $1000 \mathrm{~mm}$ in both width and height. For the centrifugal model tests conducted, the length, width and height of the model box were $1350 \times 400 \times 900 \mathrm{~mm}$ respectively.

Table 1 Basic physical properties of the compacted loess samples

\begin{tabular}{|c|c|c|c|c|c|c|c|c|}
\hline \multirow[b]{2}{*}{ Sample } & \multirow[b]{2}{*}{$\begin{array}{l}\text { Specific } \\
\text { gravity }\end{array}$} & \multicolumn{2}{|c|}{ Atterberg limits $(\%)$} & \multicolumn{3}{|c|}{ Particle size distribution $(\mathrm{mm}, \%)$} & \multirow[b]{2}{*}{$D_{50}(\mu \mathrm{m})$} & \multirow[b]{2}{*}{$\begin{array}{l}\text { Uniformity } \\
\text { coefficient }\end{array}$} \\
\hline & & Plastic limit & Liquid limit & $\begin{array}{c}\text { Clay } \\
(<0.002)\end{array}$ & $\begin{array}{c}\text { Silt } \\
(0.002-0.075)\end{array}$ & $\begin{array}{c}\text { Sand } \\
(>0.075)\end{array}$ & & \\
\hline RL1 & 2.69 & 17.1 & 25.8 & 9.29 & 80.86 & 10.15 & 26.89 & 12.04 \\
\hline RL2 & 2.69 & 15.9 & 25.7 & 9.45 & 81.92 & 8.63 & 27.10 & 12.82 \\
\hline RL3 & 2.70 & 16.1 & 25.2 & 9.43 & 81.42 & 9.15 & 26.99 & 12.98 \\
\hline RL4 & 2.71 & 16.7 & 25.7 & 9.38 & 80.79 & 9.83 & 27.63 & 12.74 \\
\hline RL5 & 2.71 & 16.0 & 25.2 & 9.29 & 81.83 & 8.88 & 27.01 & 12.20 \\
\hline
\end{tabular}

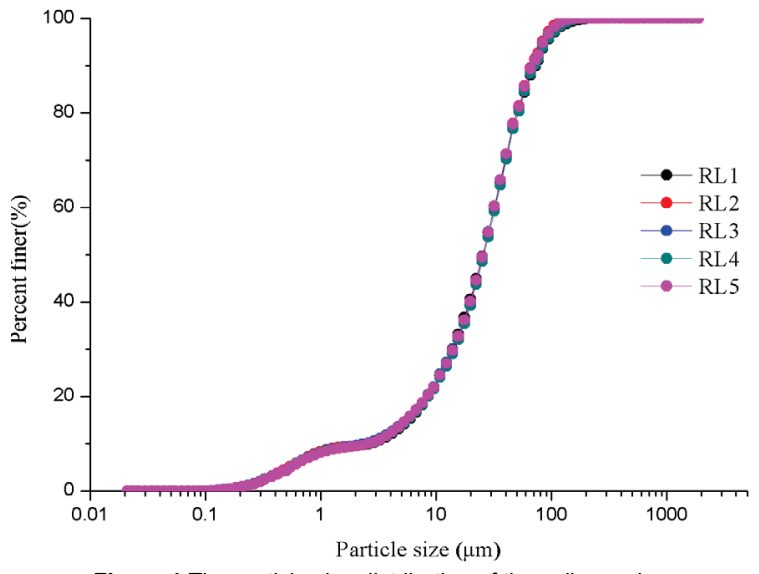

Figure 1 The particle size distribution of the soil samples

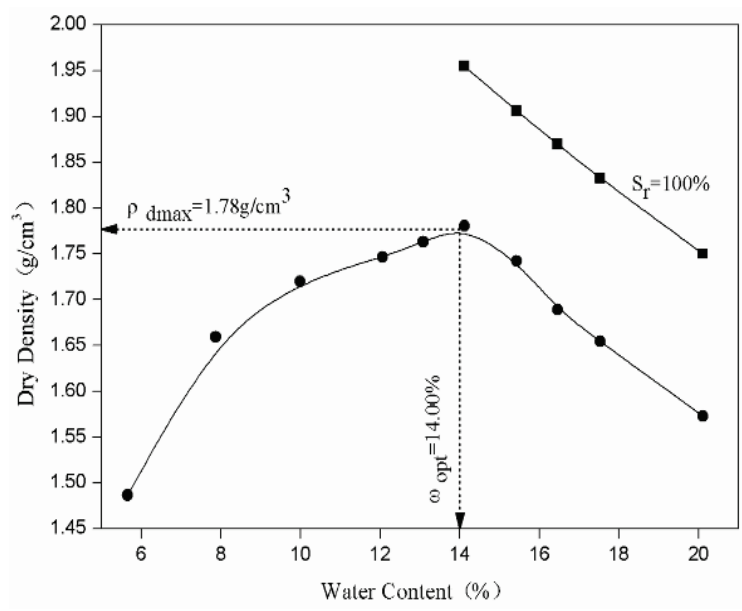

Figure 2 The compaction curve of the soil samples

\subsection{Design of the Model Test}

The lithology on both sides of the gully area of Yan'an is mainly composed of intact loess and hard sandstone, which was determined through field investigations and data analysis. Thus, the test model was made according to the typical cross section of the gully. Comparing the geometric dimensions of the model box and the actual field section, the maximum similarity ratio possible is $N=100$, which was used for this series of experimental tests.

It should be emphasized that intact loess is a typical structural soil and the unique structure determines its special engineering properties. It is very difficult to keep the original structure of the intact loess and rock bulk samples during long-distance transportation and complex model preparation processes. The main object of this study was to investigate a compacted loess filling foundation. Therefore, from the perspective of the research object and the similarity ratio of the centrifugal test, the intact loess was replaced by artificially compacted loess, and the hard sandstone mass was replaced by two bedrock boxes made of thick steel plates.

This research investigates the deformation law of the loess high-filling foundation in the gully area and then further explores the treatment technology of the joint between the filling body and the original mountain slope. In the actual full scale site, the joint on the left side of the gully had undergone a stepped treatment, while the right joint had not. Thus, the scale model used in the experimental tests was reflective of all these features. Fig. 3 shows a sketch of the scale model design with the various numbered sections explained in Tab. 2. During the tests, the settlement, earth pressure and pore water pressure were continually monitored using specialized sensors at the locations shown in Fig. 3. These precision sensors of the centrifuge had a negligible impact on the internal stress field of the measured object due to their small size and high sensitivity.

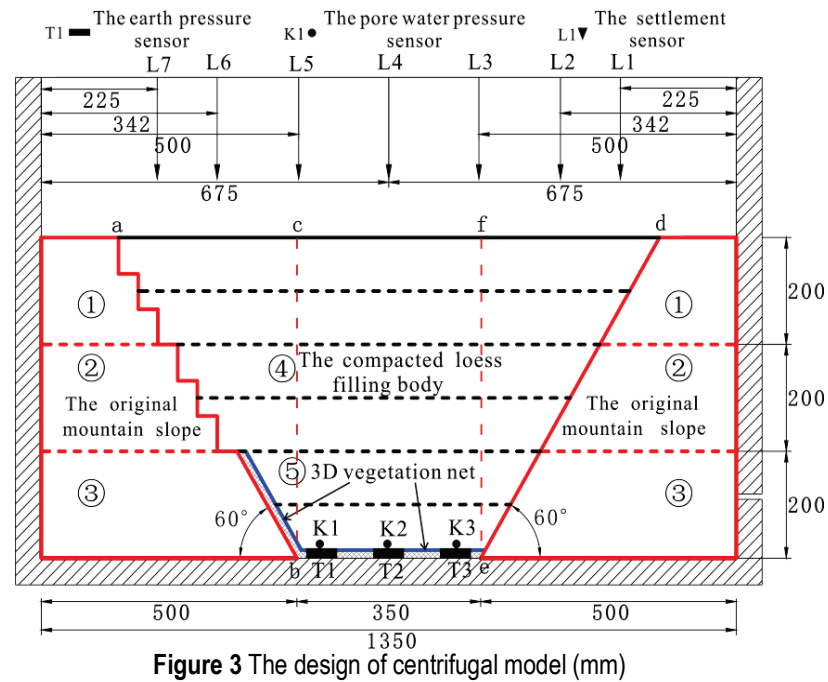

\subsection{Model Fabrication}

To begin, the water injection pipes were installed in the bedrock box and put in the correct position as per the model design. Guaranteeing the waterproof integrity of the entire model box was an essential requirement of the fabrication process. Thus, the corners of the box were double-sealed using a high quality sealant. 
The outline profile of the model was firstly drawn on the outer wall of the model box before introducing the various soil sections. The test soil from the site was filtered through a $5 \mathrm{~mm}$ sieve and then the water content was adjusted to $12.00 \%$, sealing it for $24 \mathrm{~h}$. Tamping in layers with a small-sized rammer was applied to the compaction. The dry densities are referenced in Tab. 2 . When filling the model box with soil, the thickness of each layer should be controlled to within $50 \mathrm{~mm}$. The measurement sensors and other auxiliary equipment were also installed during the fabrication process. Fig. 4 shows images of various stages of the model fabrication.

Table 2 Explanation of the various sections of the model design

\begin{tabular}{|c|c|l|}
\hline Number & Meaning & \multicolumn{1}{|c|}{ Description } \\
\hline (1) & Intact loess & $\begin{array}{l}\text { It was replaced by artificially compacted loess. The dry density was } 1.60 \mathrm{~g} / \mathrm{cm}^{3}, \text { the water content was } \\
12.00 \% .\end{array}$ \\
\hline (2) & Intact loess & $\begin{array}{l}\text { It was replaced by artificially compacted loess. The dry density was } 1.65 \mathrm{~g} / \mathrm{cm}^{3}, \text { the water content was } \\
12.00 \% .\end{array}$ \\
\hline (3) & Hard sandstone mass & $\begin{array}{l}\text { Thick steel plate was used to prepare the model, (referred to as the bedrock boxes), to replace the hard } \\
\text { sandstone mass. The boxes were hollow and capable of storing water. There were a number of drainage } \\
\text { holes on the side in contact with the filling body. The fact that the bedrock fissure water on both sides of } \\
\text { the original mountain slope seeped into the loess filling body could be represented by the bedrock boxes. }\end{array}$ \\
\hline (4) & Compacted loess filling body & $\begin{array}{l}\text { This section is consistent with the full-scale site. The dry density of the loess filling body was } 1.60 \mathrm{~g} / \mathrm{cm}{ }^{3}, \\
\text { the water content was } 12.00 \% .\end{array}$ \\
\hline (5) & 3D vegetation net & $\begin{array}{l}\text { The net was spread on the bedrock box on the left and at the bottom of the filling body. The 3D vegetation } \\
\text { net could simulate coarse aggregate with the characteristics of water diversion and permeability. The water, } \\
\text { which flowed out from the bedrock box, could be discharged. Meanwhile, it could also seep into the filling } \\
\text { body. This was in line with the characteristics of the full-scale site. }\end{array}$ \\
\hline
\end{tabular}

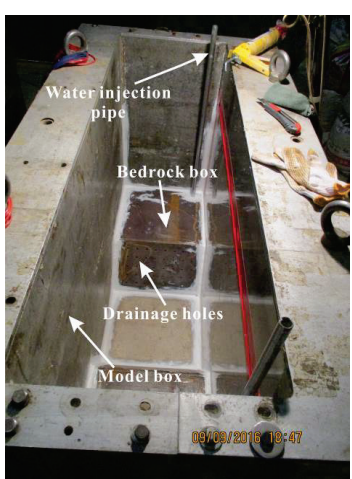

(a) Install the auxiliary equipments

Figure 4 Stages of the model fabrication process

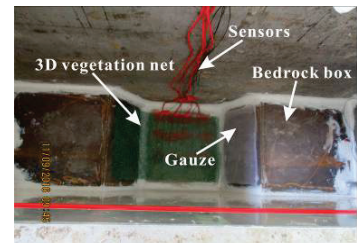

(b) Install the measurement sensors

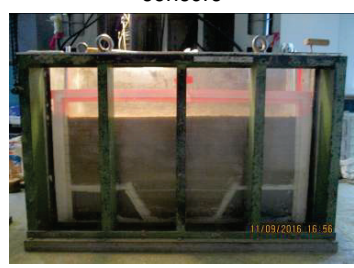

(c) The completed mode

\subsection{Test Procedure}

The testing campaign consisted of two working conditions: filling foundation stability tests with natural water content (WC1); and rising groundwater level (WC2). The test procedures are concisely explained as follows.

WC1: The model was installed into the centrifuge. When the centrifugal acceleration reached $40 \mathrm{~g}, 60 \mathrm{~g}$ and $80 \mathrm{~g}$ respectively, the acceleration was held constant for 5 min until the readings from the sensors stabilized. The centrifugal acceleration was then increased to $100 \mathrm{~g}$. The acceleration was again held constant at $100 \mathrm{~g}$ until the settlement deformation became stable. The stability criterion was that the fluctuation reading from the settlement sensors must be less than $0.2 \mathrm{~mm}$. Finally, a controlled deceleration, or centrifugal unloading, was performed until the machine was shut down.

WC2: The model was not altered after the WC1 test was completed. Rather, water was introduced to the bedrock boxes through the injection pipes until they were filled, ensuring the same water injection rate of the two bedrock boxes. Then while testing immediately, the centrifugal acceleration was uniformly increased to $100 \mathrm{~g}$.
It was then held constant at $100 \mathrm{~g}$ for $35 \mathrm{~min}$. The WC2 test was then stopped. The purpose of the WC2 test was to analyze the deformation law of the filling foundation under a rising water level scenario caused by the permeation of bedrock fissure water from the original mountain slope.

\section{TEST RESULTS \\ 4.1 WC1: Test Results in Natural Water Content}

The consolidation process of the filling foundation under a natural water content scenario was simulated in WC1. The test was carried out for $30 \mathrm{~min}$ at an acceleration of $100 \mathrm{~g}$, which is equivalent to the consolidation of the full-scale foundation over duration of 208 days.

\subsubsection{Settlement}

Several cracks appeared on the surface of the completed test model. These cracks were particularly severe in the regions close to the joints, as can be seen in Fig. 5. The ground surface settlement curve of each measuring point in $\mathrm{WC1}$ is shown in Fig. 6.

Fig. 6 reveals that the settlement deformation mainly occurred as the centrifugal acceleration increases, and that the settlement rate also increased in the process. The thicker the filling soil, the greater the settlement is, and an uneven settlement occurs on the surface in the case of natural water content. The uneven settlement at each measuring point is magnified as the acceleration increases, ultimately leading to ground surface cracks in the model. The values of the sensors L7, L6, L5 and L1, L2, L3 respectively reflected the settlement on the left and right filling foundations, whose joints went through the stepped treatment and untreated process. The original mountain slope had the same gradient, so the filling thickness in the corresponding positions on both sides of the model were the same; i.e., L7-L1, L6-L2, L5-L3. 


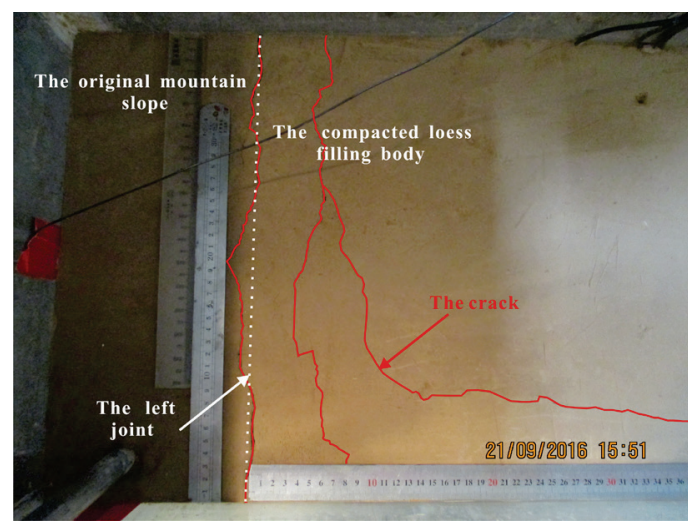

(a) The cracks around the left joint

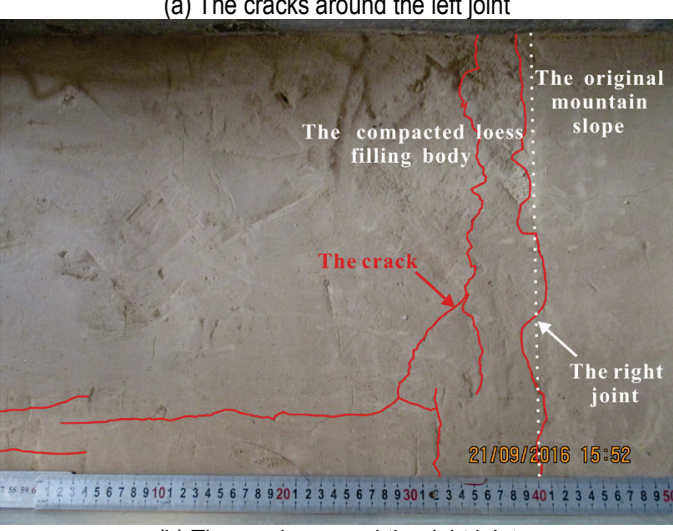

(b) The cracks around the right joint

Figure 5 The severe cracks around the joints

Horizontal position ( $\mathrm{mm}$ )

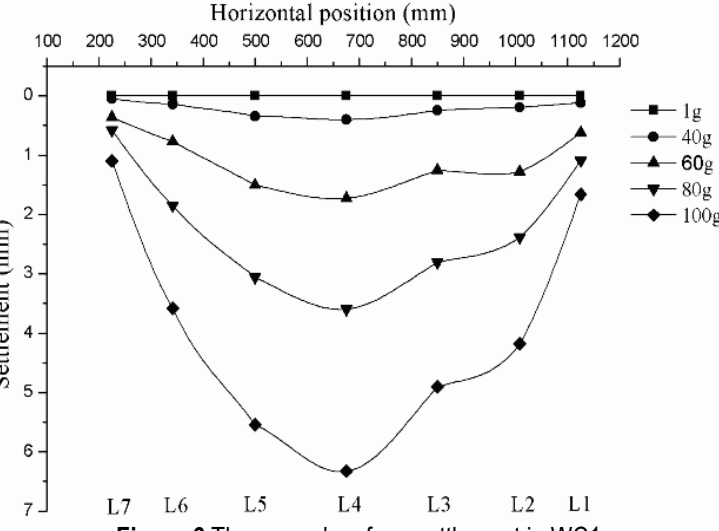

Figure 6 The ground surface settlement in WC1

According to the test data, the differential settlement of each measuring point increased with the increase in centrifugal acceleration. L7 and L6 had less settlement than L1 and L2 respectively, which indicates that the stepped treatment of the joint was helpful in controlling the settlement of the filling foundation. However, comparing L5 and L3, the settlement of L5 was greater than L3. As the original mountain slope was quite steep, as reflected in zones abca and defd of Fig. 3, the filling body above the joint had a tendency to downslide as the centrifugal acceleration increased. This, in turn, will squeeze the filling body in the central section (zone befcb of Fig. 3) and reduce the settlement in this area to a certain extent. Compared with the right side of the model, the stepped treatment to the joint on the left side delays the downslide tendency of the upper filling body, making the squeezing action of the portion on the right side more intense than that on the left side. This reduced the settlement of L3 to some extent, which finally led to the settlement of L3 being less than that of L5.

\subsubsection{Earth Pressure}

In order to study the vertical earth pressure distribution, the earth pressure sensors $\mathrm{T} 1$ and $\mathrm{T} 3$ were placed adjacent to the left and right joints respectively. T2 was placed in the center of the filling body (see Fig. 3). The measurement results of the vertical earth pressure are shown in Fig. 7.

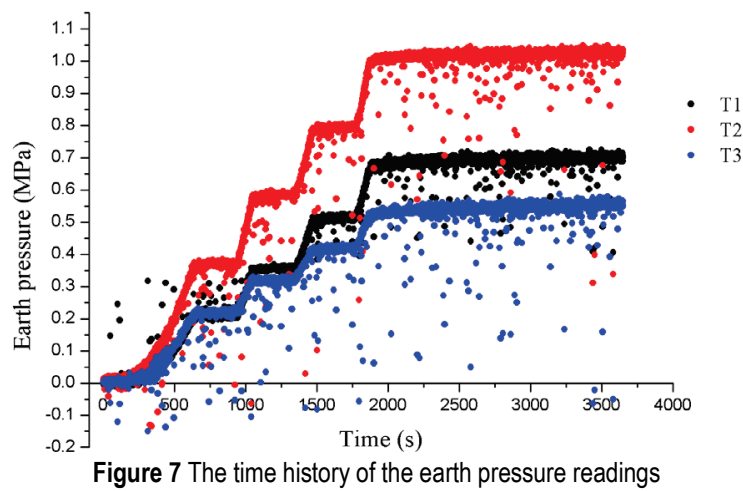

With the increase of the centrifugal acceleration, the earth pressure also increased, as shown in Fig. 7. The earth pressure changed step by step, in keeping with the stepped acceleration profile, and had no drastic changes until the acceleration reached $100 \mathrm{~g}$. T2 was buried in the central portion of the filling body and the measured values were essentially the same as theory would predict. T1 was located at the bottom of the joint which underwent the stepped treatment, while T3 was located at the bottom of the joint which had no treatment. The earth pressure measurements of $\mathrm{T} 1$ and $\mathrm{T} 3$ were less than $\mathrm{T} 2$ at each centrifugal acceleration stage. When the acceleration was greater than or equal to $60 \mathrm{~g}$, the measured value of $\mathrm{T} 3$ was smaller than T1 and the difference between the two values magnified as the acceleration further increased. Thus, these results show that when the centrifugal acceleration reached $60 \mathrm{~g}$, the filling body above the joints had squeezed the filling body in the central portion and the squeezing action from the right was more intense than that from the left. This squeezing action could partially counteract the filling load. The result that $\mathrm{T} 3<\mathrm{T} 1<\mathrm{T} 2$, and given the fact that the self-load of the filling body is a major precipitating factor in settlement, also supports the result that $\mathrm{L} 3<\mathrm{L} 5$.

The results of the above analysis suggest that adopting the stepped treatment method to overlap the original mountain slope and the filling body has a positive effect on reducing the settlement of the filling body above the joint. However, it is not conducive to controlling the settlement of the adjacent filling body. This largely relates to the downslide tendency of the filling body above the joint. Furthermore, the downslide tendency is also associated with the geological engineering conditions of the original mountain. This requires further study.

\subsection{WC2: Test Results in Rising Groundwater Level}

The WC2 test was maintained for $35 \mathrm{~min}$ at an acceleration of $100 \mathrm{~g}$. This is equivalent to the full-scale foundation consolidating for duration of 243 days while the groundwater level in the filling body is gradually increasing. 


\subsubsection{Settlement}

The ground surface settlement curve of each measuring point in the WC2 test is shown in Fig. 8. It should be highlighted here again that the foundation had already been consolidated for 208 days (full scale equivalent) in natural water content. Thus, the compaction degree and strength had been greatly improved. However, with the rise of the groundwater level in the filling body, additional settlement occurred to the filling foundation. The thicker the filling soil, the greater the additional settlement is. The additional settlement was significantly smaller than that in the natural state. This indicates that when the compaction of the filling was improved, additional settlement caused by the rising groundwater level can be greatly reduced. Thus, compactness should be enhanced as much as possible in filling engineering projects.

The qualitative feature of the ground surface settlement with natural water content was similar to that in the rising groundwater level. The settlement in L7 and L6 was less than that in L1 and L2, and L5 was greater than L3. However, the differences between the L5 and L3 values are very small at: $0.005 \mathrm{~mm}$ in $1500 \mathrm{~s}(100 \mathrm{~g})$; $0.006 \mathrm{~mm}$ in $2000 \mathrm{~s}(100 \mathrm{~g}) ; 0.007 \mathrm{~mm}$ in $2500 \mathrm{~s}(100 \mathrm{~g})$; and $0.006 \mathrm{~mm}$ in $3000 \mathrm{~s}(100 \mathrm{~g})$. Despite the high acceleration of $100 \mathrm{~g}$, these differences did not increase with the rise in groundwater level. This is because the settlement in L5 and L3 was simultaneously affected by the rise of the groundwater level and the squeezing action of the filling body above the joint on the left and right sides. On the one hand, the rising groundwater level could cause additional settlement, resulting in an increase of the total settlement. On the other hand, the strength of the deep soil is reduced due to water saturation, which in turn is beneficial to the downslide of the filling body above the joint, enhancing the squeezing action and reducing the settlement.

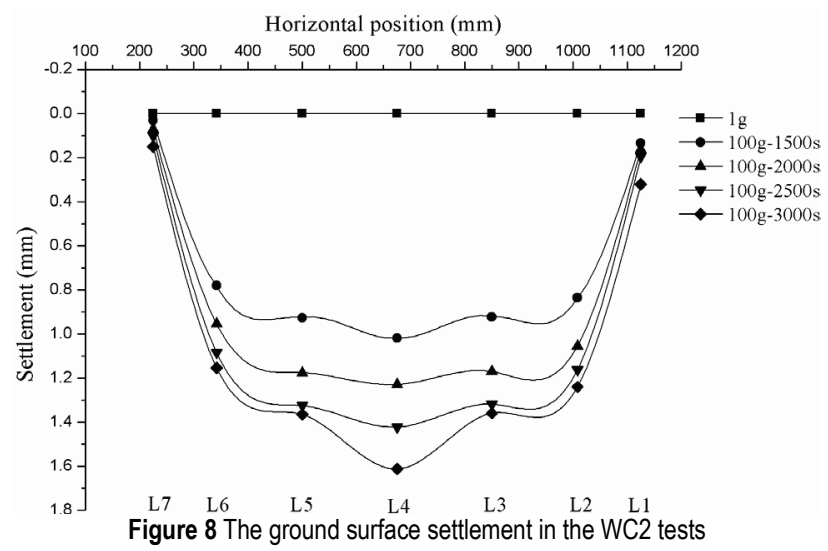

During the WC2 test, the earth pressure sensors failed and so the data were not collected. Thus there is no pressure analysis reported in this section.

\subsubsection{Pore Water Pressure}

$\mathrm{K} 1, \mathrm{~K} 2$ and $\mathrm{K} 3$ are the pore water pressure sensors, the location of which is shown in Fig. 3. As with the earth pressure sensors, K1 and K3 were placed adjacent to the joints and $\mathrm{K} 2$ was in the center of the filling body. The pore water pressure curves are shown in Fig. 9.

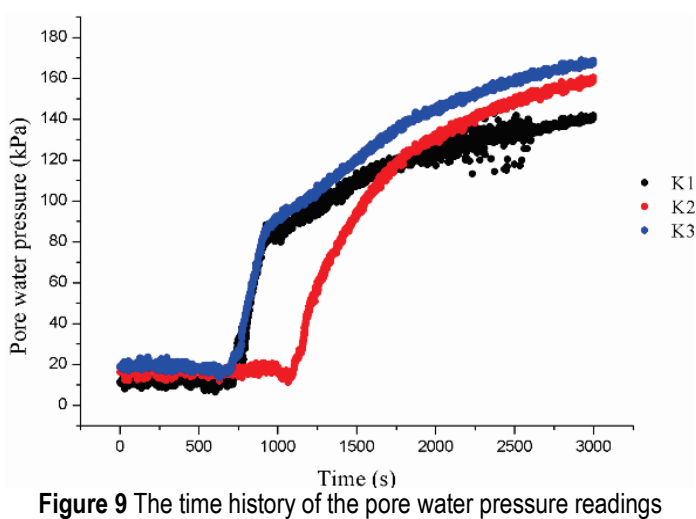

The centrifugal acceleration reached $100 \mathrm{~g}$ at $900 \mathrm{~s}$ and remained constant thereafter. The water in the bedrock boxes seeped through the vertical section where $\mathrm{K} 1$ and $\mathrm{K} 3$ were located, so the pore water pressure changed first in $\mathrm{K} 1$ and $\mathrm{K} 3$. The change in $\mathrm{K} 2$ lagged behind because of the water permeation from both sides to the centre. After $1800 \mathrm{~s}$, it is found that the pore water pressure of K3 was the highest, followed by K2 and then $\mathrm{K} 1$. If symmetric, the pore water pressure of $\mathrm{K} 3$ and $\mathrm{K} 1$ should always be greater than that of $\mathrm{K} 2$. However, due to the positioning of the $3 \mathrm{D}$ vegetation net, $\mathrm{K} 1$ was less than $\mathrm{K} 2$, as shown in Fig. 9. The water could seep but also could be diverted by the $3 \mathrm{D}$ vegetation net. Some of the water flowing out of the bedrock box laterally seeped into the filling body, while some water flowed downward along the $3 \mathrm{D}$ vegetation net with gravity. Compared with $\mathrm{K} 1$, the same amount of water would accumulate and seep into the filling body because there were no diversion measures on the side of K3. The tests also demonstrated that the residual water of the left bedrock box was significantly less than that on the right. The pore water pressure was analysed at eight different times during the WC2 test, and the groundwater level at each moment was calculated inversely. The results are shown in Fig. 10.

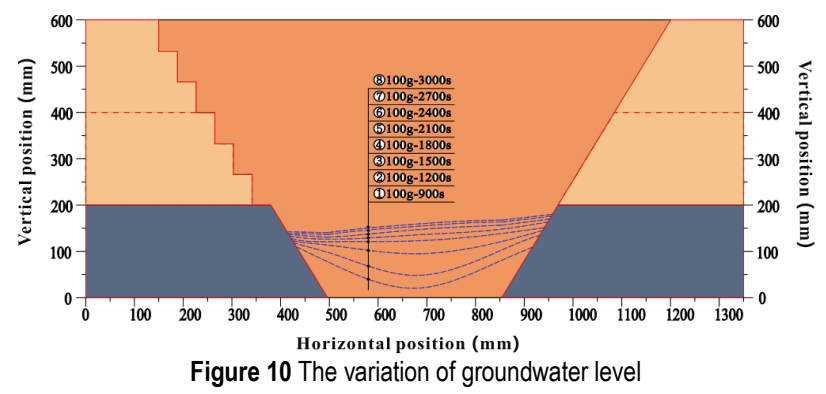

From Fig. 10, the moisture in the deep filling soils is constantly changing. It was found that compared with the right side of the model, the groundwater level on the left side, where the $3 \mathrm{D}$ vegetation net is located, was lower. In parallel, the rising groundwater level, coupled with the increasing rate of saturated thickness of the filling body, gradually decreased. This indicates that this feature could play an important role in controlling the rise of groundwater level. For example, when filling engineering activities are carried out in the gully area, permeable materials such as coarse aggregate could be arranged at the joint between the filling body and the original bedrock mass. They could then be compacted to form the permeable belt which can promote the diversion of the 
bedrock fissure water. Finally, by connecting the permeable belt to the drainage pipes at the bottom of the gully, the water would be discharged along the pipeline and the infiltration capacity of the filling body would be reduced. This would be conducive to the stability of the filling foundation and can prevent the large postconstruction settlement.

\subsubsection{The Relationship between Settlement and Rising Groundwater Level}

As shown in Fig. 11, a relationship between the ground surface settlement and the groundwater level under a centrifugal acceleration of $100 \mathrm{~g}(1000-3000 \mathrm{~s})$, was established.

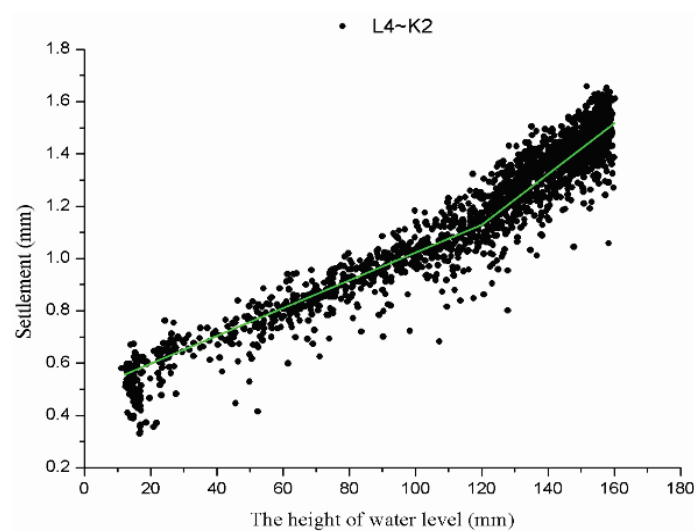

(a) The relationship curve of $L 4 \sim K 2$ - $\mathrm{L} 3 \sim \mathrm{K} 3 \cdot \mathrm{L} 5 \sim \mathrm{K} 1$

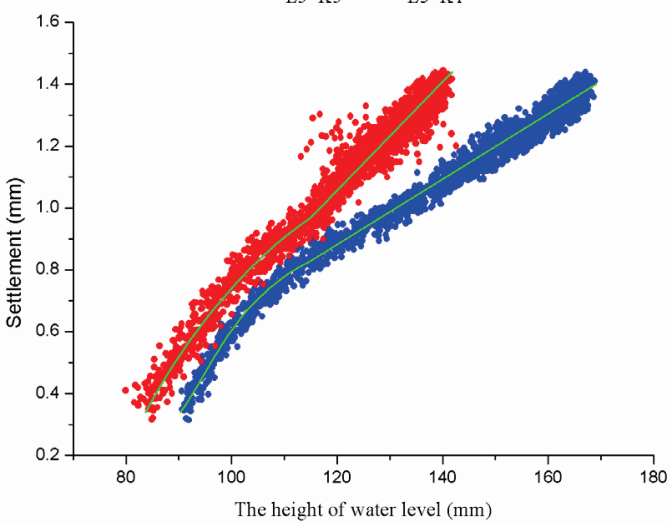

(b) The relationship curves of L3 K3 and L5 K1

Figure 11 The relationships between the groundwater level and the ground surface settlement

After consolidation for a certain period of time in the natural water content test, the homogeneity of the filling foundation had been improved. Fig. 11(a) shows the relationship between the ground surface settlement and the groundwater level in the center of the filling foundation (L4-K2). This location was the farthest from the boundary and thus was least affected by the boundary conditions. The relationship is well approximated by two straight lines of different slopes which intersected at 120 $\mathrm{mm}$. When the groundwater level increased above 120 $\mathrm{mm}$, the settlement amplitude noticeably increased and the filling foundation became unstable. Fig. 11(b) shows the relationship between the ground surface settlement and the groundwater level adjacent to the joints, and it is more complex than that in Fig. 11(a). The settlement in L5 was larger than that in L3 for the same water content, which indicates that the squeezing action of the filling body above the joint on the left side of the model was weaker than that on the right side. When the groundwater level was less than $120 \mathrm{~mm}$, a nonlinear relationship was observed in both L3-K3 and L5-K1. Conversely, when the level was greater than $120 \mathrm{~mm}$ a linear relationship was found. A possible explanation for this is that when the groundwater level increased to $120 \mathrm{~mm}$, the filling foundation above the joint on the right side of the model was unstable and the squeezing action was maximized. The filling foundation on the left side remained stable, influenced by the stepped treatment to the joint.

To summarize, an effective drainage system should be established during the whole process of high loess filling engineering in a gully area to prevent the destabilization of the filling foundation with rising groundwater level. In addition, the treatment technology of the joints between the original mountain slope and the filling body should be reasonably designed based on the geological characteristics of the original mountain slope.

\section{CONCLUSIONS}

This study investigated the deformations of highfilling foundation of loess in a gully area and the treatment technology utilized between the original mountain slope and the filling body. Experimental centrifugal model tests were utilized to examine these features. The key conclusions from the research are as follows

The filling in the gully area will inevitably break the regional balance of groundwater seepage and will easily lead to a rise in groundwater level. It will directly affect the stability of the filling foundation. Various treatment technologies utilized at the joint between the original mountain slope and the filling body has different effects on the post-construction settlement of the filling foundation.

Under the condition of natural water content, the settlement rate of the foundation increases with an increase in centrifugal acceleration. The thicker the filling soil, the larger the settlement is. Under the condition of rising groundwater level, the filling foundation shows a qualitatively similar settlement profile as the natural state. With a rise in groundwater level, additional settlement occurs to varying degrees, which leads to the instability of the filling foundation. Enhancing the initial compactness of the foundation is conducive to reducing this additional settlement induced by rising groundwater.

The overlap between the filling body and the original mountain slope includes two regions. The first is the filling versus the intact loess and the second is the filling versus the original bedrock mass. For the overlap between the filling and the intact loess, adopting the stepped treatment method to the joint helps to reducing the settlement of the filling foundation above the joint, but restricts the squeezing action from this portion of filling. It will not contribute to controlling the settlement of the adjacent filling body. For the overlap between the filling and the original bedrock mass, it was found that installing permeable materials at the joint and compacting them to form a permeable belt (which in turn is connected to the drainage pipeline laid at the bottom of the gully) can 
advantageously discharge the bedrock fissure water so that the water infiltration and the rising groundwater level can be controlled. This is beneficial for the stability of the filling foundation.

\section{Acknowledgment}

This research was funded by the Scientific and technological innovation project of Shaanxi province (NO. 2012KTZD03-03, 2012KTZD03-04, 2014KTZD03-0102). The authors are thankful to Mr Xue-dong Zhang and Jian-hui Liang for their assistance during this work in China's Institute of Water Resources and Hydropower Research

\section{REFERENCES}

[1] Editorial Board of China Natural Geography; Chinese Academy of Sciences. China physical geography, morphology. Science Press, Beijing, 1980.

[2] Chen, Y. Z., Jing, K., \& Cai, Q. G. (1988). Modern erosion and management. Science Press, Beijing.

[3] Comprehensive Survey Team on Loess Plateau of Chinese Academy of Sciences. Studies on division mapping for integrated management and development of the Loess Plateau region. China Economic Publishing House, Beijing, 1990.

[4] Li, P. Y., Qian, H., \& Wu, J. H. (2014). Accelerate research on land creation. Nature Comment, 510, 29-31. https://doi.org/10.1038/510029a

[5] Biot, M. A. (1941). General theory of three-dimensional consolidation. J. of Applied Phys, 12, 2-18. https://doi.org/10.1063/1.1712886

[6] Schiffrnan, R. L. \& Chen, A. T. F. (1969). An analysis of consolidation theories. $J$. of $S$. M. and F. Division, 95(SM1), 50-70.

[7] Yin, J.-H. \& Graham, J. (1989). Viscous- Elastic- Plastic Modeling of One-Dimensional Time-dependent Behavior of Clays. Can. Geotech. J., 26(2), 199-209. https://doi.org/10.1139/t89-029

[8] Brebbia, C. A. \& Walker, S. (1980). Boundary element in engineering. London, Newnes-Butter worths, 10-31.

[9] Liu, G. R. \& Gu, Y. T. (2001). A point interpolation method for two-dimensional solid. Int. J. Numer. Methods Engrg., 50, 937-951.

https://doi.org/10.1002/1097-0207(20010210)50:4<937::AIDNME62>3.0.CO;2-X

[10] Karim, M. R. (2001). Analysis of Biot's consolidation using Element-free Galerkin method. Dissertation for Master degree, National University of Singapore, 2-78.

[11] Tan, S. A. \& Chew S. H. (1996). Comparison of the hyperbolic and Asaoka observational method of monitoring consolidation with vertical drains. Soils and Foundation, 36(3), 31-42. https://doi.org/10.3208/sandf.36.3_31

[12] Gompertz, B. (1925). On the Function Expressive of the law of Human Mortality, and on a new Method of Determining the Value of Life Contingencies. Philosophical Transactions of the Royal Society, 513-585.

[13] Hosiya, M. \& Sotoh, A. (1992). Extended Kalman Filterfinite Element for Geotechnical Problems. Y. Klineds, ASCE / New York.

[14] Morsy, M. M., Morgenstern, N. R., \& Chan, D. H. (1995). Simulation of creep deformation in the foundation of Tar Island Dyke. Canadian Geotechnical Journal, 32(6), 10021023. https://doi.org/10.1139/t95-098

[15] Shi, J. S., Ortigao, J. A. R., \& Bai, J. L. (1998). Modular neural networks for predicting settlements during tunnelling. J. Geotech. Geoenviron. Engrg, ASCE, 124(5), 389-395. https://doi.org/10.1061/(ASCE)1090-0241(1998)124:5(389)

[16] Shen, C. K., Li, X. S., Ng, C. W. W., Van Laak, P. A., Kutter, B. L., Cappel, K., \& Tauscher, R. C. (1998). Development of a geotechnical centrifuge in Hong Kong. In: Kimura T., Kusakabe O., Takemura J., editors. Proceedings of Centrifuge'98 / Tokyo, 1, 13-18.

[17] Ng, C. W. W., Van Laak, P. A., Zhang, L. M., Tang, W. H., Zong, G. H., Wang, Z. L., Xu, G. M., \& Liu, S. H. (2002). Development of a four-axis robotic manipulator for centrifuge modeling at HKUST. Proceedings of the International Conference on Physical Modelling in Geotechnics / St John's Newfoundland, Canada, Balkema, 71-76.

[18] Chaney, R. C.; Demars, K. R.; Dewoolkar, M. M.; Ko, H. Y.; Stadler, A. T.; Astaneh, S. M. F. (1999). A substitute pore fluid for seismic centrifuge modeling. Geotech Testing J., 22(3), 196-210. https://doi.org/10.1520/GTJ11111J

[19] Almeida, M. S. S. \& Parry, R. H. G. (1984). Penetrometer apparatus for use in the centrifuge during flight. Proc. Symp. Application of Centrifuge Modelling to Geotechnical Design / Manchester, England, 65-67.

[20] Koseki, J., Koga, K., Takahashi, A., Leung, C. F., Lee, F. H., \& Tan, T. S. (1994). Liquefaction of sandy ground and settlement of embankments. Proceedings of Centrifuge '94 / Singapore, 215-220.

[21] Taboada, V. M., Carvajal, H. M., Okamura, M., Kimura, T., Kusakabe, O., \& Takemura, J. (1998). Effect of input frequency on the dilation behavior of an infinite slope of loose sand. Proceedings of Centrifuge'98 / Tokyo, 315-320.

[22] Bolton, M. D. \& Shama, J. S. (2001). Centrifugal and numerical modelling of reinforced embankments on soft clay installed with wick drains. Geotextiles and Geomembranes, 19(1), 23-44. https://doi.org/10.1016/S0266-1144(00)00009-1

[23] Jing, H. J., Hu C. S., \& Wang B. G. (2005). Study on settlement and deformation laws of high loess-fill embankment. Chinese Journal of Rock Mechanics and Engineering, 24(Supp. 2), 5845-5850.

[24] Weng, X. L., Wang, W., \& Liu, B. J. (2011). Model test on deformation characteristics of widening collapsible loess roadbed and dynamic compaction method treatment effect. China Journal of Highway and Transport, 24(2), 17-22.

[25] Hu, C. M., Mei, Y., Liu, Z. R., \& Wang, X. Y. (2012). Deformation mode and stability analysis of high sticking slope of collapsible loess. Chinese Journal of Rock Mechanics and Engineering, 31(12), 2585-2592. https://doi.org/10.3969/j.issn.1000-6915.2012.12.024

[26] Wang, C. D., Wang, B. L., Wang, X., \& Zhou, S. H. (2011). Analysis of settlement controlling effect of pile-net composite foundation on collapsible loess by centrifugal model tests. Journal of the China Railway Society, 33(4), 84-92. https://doi.org/10.3969/j.issn.1001-8360.2011.04.013

[27] Mei, Y., Hu, C. M., Wei, Y. F., Zhang, W. C., Yuan, Y. L., \& Wang, X. Y. (2015). A centrifugal test study of the deformation of high backfill foundation in deep ravine of Q2 and Q3 loess. Rock and Soil Mechanics, 36(12), 34733481. https://doi.org/10.16285/.rsm.2015.12.018

[28] Cascetta, F., Musto, M., Rotondo, G., \& Barbato, L. (2016). The influence of the filling percentage traffic on required ventilation thrust in road tunnel. International Journal of Heat and Technology, 34(Special Issue 2), S451-S457. https://doi.org/10.18280/ijht.34S237

[29] Yuan, Q. N., Yuan, Q. Y., \& Du, F. L. (2016). The characteristics research of solid-liquid two-phase fluid in the filling process of fried pepper sauce. International Journal of Heat and Technology, 34(2), 221-226. https://doi.org/10.18280/ijht.340210 
[30] Standardization Administration of China (SAC), Ministry of Water Resources. China National Standards GB/T501231999: Standard for Soil Test Method. China Planning Press, Beijing, 1999.

\section{Contact information:}

Kai WU, PhD Candidate

College of Geology Engineering and Geomatics, Chang'an University,

Middle-section of Nan'er Huan Road Xi'an,

ShaanXi Province, 710064, P. R. China

E-mail:wk2014026016@foxmail.com

Wankui NI, PhD, Professor (Corresponding author)

College of Geology Engineering and Geomatics, Chang'an University,

Middle-section of Nan'er Huan Road Xi'an,

ShaanXi Province, 710064, P. R. China

E-mail: nnwwkk@126.com

Longshuai XU, Master Candidate

College of Geology Engineering and Geomatics, Chang'an University,

Middle-section of Nan'er Huan Road Xi'an,

ShaanXi Province, 710064, P. R. China

E-mail:1510176606@qq.com 